IZA DP No. 6963

The Impact of Education and Occupation on Temporary and Permanent Work Incapacity

Nabanita Datta Gupta

Daniel Lau

Dario Pozzoli

October 2012 


\title{
The Impact of Education and Occupation on Temporary and Permanent Work Incapacity
}

\author{
Nabanita Datta Gupta \\ Aarhus University and IZA \\ Daniel Lau \\ Cornell University \\ Dario Pozzoli \\ Aarhus University and IZA
}

\section{Discussion Paper No. 6963 \\ October 2012}

\author{
IZA \\ P.O. Box 7240 \\ 53072 Bonn \\ Germany \\ Phone: +49-228-3894-0 \\ Fax: +49-228-3894-180 \\ E-mail: iza@iza.org
}

\begin{abstract}
Any opinions expressed here are those of the author(s) and not those of IZA. Research published in this series may include views on policy, but the institute itself takes no institutional policy positions. The IZA research network is committed to the IZA Guiding Principles of Research Integrity.

The Institute for the Study of Labor (IZA) in Bonn is a local and virtual international research center and a place of communication between science, politics and business. IZA is an independent nonprofit organization supported by Deutsche Post Foundation. The center is associated with the University of Bonn and offers a stimulating research environment through its international network, workshops and conferences, data service, project support, research visits and doctoral program. IZA engages in (i) original and internationally competitive research in all fields of labor economics, (ii) development of policy concepts, and (iii) dissemination of research results and concepts to the interested public.
\end{abstract}

IZA Discussion Papers often represent preliminary work and are circulated to encourage discussion. Citation of such a paper should account for its provisional character. A revised version may be available directly from the author. 


\section{ABSTRACT}

\section{The Impact of Education and Occupation on Temporary and Permanent Work Incapacity ${ }^{*}$}

This paper investigates whether education and working in a physically demanding job causally impact temporary work incapacity, i.e. sickness absence, and permanent work incapacity, i.e. the inflow to disability via sickness absence. Our contribution is to allow endogeneity of both education and occupation by estimating a quasi-maximum-likelihood discrete factor model. Data on sickness absence and disability spells for the population of older workers come from the Danish administrative registers for 1998-2002. We generally find an independent role of both education and occupation on temporary work incapacity only. Having at least primary education reduces women's (men's) probability of temporary work incapacity by $16 \%$ (38\%) while working in a physically demanding job increases it by $37 \%(26 \%)$. On the other hand, conditional on sickness absence, the effects of education and occupation on permanent work incapacity are generally insignificant.

JEL Classification: I12, I20, J18, C33, C35

Keywords: $\quad$ work incapacity, education, occupation, factor analysis, discrete factor model

Corresponding author:

Dario Pozzoli

Aarhus University

Department of Economics and Business

Fuglesangs Allé 4

8210 Aarhus

Denmark

E-mail: dpozzoli@asb.dk

\footnotetext{
* We would like to thank Jakob Arendt, Pilar Garcia-Gomez, Hans van Kippersluis, Petter Lundborg, Filip Pertold, David C. Ribar and Chan Shen for helpful comments and suggestions. We also appreciate comments from participants at seminars organized by Lund University, University of Maastricht, The Danish Institute of Governmental Research (AKF) and The Swedish Institute of Social Research (SOFI), and participants at the workshop on Health, Work and the Workplace, Aarhus University, May 2011, at the 32nd Nordic Health Economists Study Group Meeting, Odense, August 2011, and at the ASHE conference in Minneapolis, June 2012. Funding from the Danish Council for Independent Research-Social Sciences, Grant no.x09-064413/FSE is gratefully acknowledged. The usual disclaimer applies.
} 


\section{Introduction}

Disability among working-age individuals is arguably the most important health parameter for policy purposes. Despite the impressive medical breakthroughs which have improved aggregate health over the last decades, persistently large numbers of people of working age leave the workforce and rely on health-related income support like sickness absence and disability benefits (Autor and Duggan, 2006). This trend is witnessed in virtually all OECD countries today, including Denmark, and the lost work effort of these individuals represent a great cost to society. ${ }^{1}$ Health-related problems, thus, are increasingly proving to be an obstacle to raising labor force participation rates and keeping public expenditures under control.

Previous, mainly descriptive, research has shown a significant educational gradient in the onset of long-term sickness absence and disability (see e.g. Fried and Guralnik, 1997, Freedman and Martin, 1999, Cutler and Lleras-Muney, 2007) and the few studies that have estimated causal effects of education on self-reported disability status also find significant negative effects (Kemptner et al., 2011, Oreopoulous, 2006). An occupational gradient in health is also well documented (Case and Deaton, 2005; Fletcher et al. 2009; Morefield et al. 2012; for Denmark, see Lund et al., 2004). Yet no study up to now has tried to simultaneously uncover the relationships between these variables and health deterioration of old workers.

\footnotetext{
${ }^{1} \mathrm{On}$ average, expenditures on disability and sickness benefits account for about $2 \%$ of GDP in OECD countries, about 2.5 times what is spent on unemployment benefits. This ranges from $0.4 \%$ for Canada to $5 \%$ in Norway. In the US it is $1.4 \%$ of GDP, while in Denmark $3.1 \%$ of GDP is spent annually (OECD, 2005).
} 
A possible theoretical basis for a socioeconomic gradient in health arising from both education and the nature of jobs is provided in the modified version of Grossman's 1972 intertemporal model of health (Muurinen, 1982; Muurinen and Le Grand, 1985; Case and Deaton, 2005). According to this theoretical setup, health deteriorates over time but it is maintained by education through various channels. First, education raises the efficiency of inputs needed to restore health by e.g. following directions on medicine packages (Goldman and Lakdawalla, 2001). Second, education gives people greater health knowledge (Kenkel, 1991). A third channel proposed by Fuchs (1982) and Becker and Mulligan (1997) is that education can change people's rate of time preferences and thereby lead them to invest in better health. A final pathway between education and health is that educated individuals can avoid physically demanding jobs and this reduces the rate at which their health deteriorates (Muurinen, 1982, Muurinen and Le Grand, 1985, Case and Deaton, 2005). That is, health is also affected by the extent to which "health capital" is used in consumption and in work. Some consumption activities are harder on the body than others and manual or physically demanding work is harder on the body than non-manual work. Allowing for the health deterioration rate to depend on physical effort provides an explanation for why health may deteriorate faster with age among the low-educated or manual workers.

In a health care system with universal access and insurance such as the Danish one, we would expect financial constraints to be less binding for the purpose of meeting 
health needs. Maurer (2007) analyzes comparable cross-national data from the SHARE on 10 European countries. Estimating health care utilization using flexible semi- and non-parametric methods, there is no evidence of any education-related health gradient in Denmark, and education is typically a good proxy for permanent income. ${ }^{2}$ Another characteristic of the Danish labor market that works against finding work-related health-deterioration is a relatively high degree of employer accommodation paid for by the municipalities. Danish workplaces are reportedly among the most accommodating in Europe, especially after the twin pillars of corporate social responsibility and activation of marginalized groups were incorporated starting from the mid-1990s (Bengtsson, 2007). Larsen (2006) reports that almost half of the private and public workplaces in Denmark with at least ten employees and with a least one employee above the age of 50 make an effort to retain older workers. These institutional features imply that any work-related health deterioration in manual jobs found in Denmark is probably only a lower bound of what can be found in other settings.

At the same time, prior research has convincingly shown that sickness absence and disability are forms of moral hazard behavior in settings where agents are fully insured, e.g. in welfare states with generous benefit provision for health-related problems (for instance, Johansson and Palme, 2005). Compensation-seeking behavior can be of two types: ex ante moral hazard, implying individuals do not undertake sufficient measures or investments to prevent diseases/disability or ex post moral hazard, according

\footnotetext{
${ }^{2}$ Education health gradients are found in Greece, Italy and to a certain extent in Austria and Switzerland, but not in Spain, France, the Netherlands or Sweden. Although the results are not as clear-cut for Germany, over most of the profile the utilization appears fairly flat.
} 
to which individuals claim compensation for hard to verify diseases, overplay their symptoms or even withhold their labor supply during the awardings' phase such as continuing to be on sickness absence while waiting for a decision on a disability application (Bolduc et al., 2002). In Denmark, municipalities pay for necessary workplace adaptations, provide employers with wage subsidies and give sick-listed workers a form of social support that facilitates continued work without risk of benefit loss. Educated people and individuals working in non-manual jobs have lower expected payoffs from disability insurance or sickness benefits, i.e. they would be less prone to compensationseeking behaviour. Although direct measures of moral hazard behavior are not present in register data, they constitute an important source of unobserved heterogeneity that needs to be accounted for.

The aim of this paper is to empirically model and estimate the relationships between education, working in a physically demanding job and individual health-related exit from the labor market. More specifically, our study adds to the literature in this field in several respects. To the best of our knowledge, this is the first attempt to distinguish between whether lower labor market attrition among educated working-age individuals is due to less wear-and-tear and fewer accidents on their jobs, or whether it is due to the protective effect of education leading to greater health knowledge, more caution and greater efficiency in health investments. Thus, our empirical analysis singles out the indirect effect of education on health working through occupational choice from the direct effect. Second, by applying clear identification strategies based on a 
major educational reform and on the historical characteristics of local labor supply, we aim to uncover causal impacts of both education and working in a physically demanding job on sickness absence and disability. By modeling the pathway of disability exit going through sickness absence, we also aim to explore similarities and differences in the factors affecting behavior for these two processes. Third, to construct a highly reliable measure of the physical demands of jobs, we use very detailed skill information in the Dictionary of Occupational Titles (DOT) data in conjunction with the information provided in the US census occupation codes and the Danish register's occupation codes. ${ }^{3}$ Furthermore, whereas much of the previous research on disability is based on error-prone self-reported measures, we access more objective register-based indicators. The reliability of self-reported measures has in fact been questioned because of reporting heterogeneity (Johns, 1994, Bago d'Uva et al., 2008, Kapetyn et al., 2007, Grøvle, 2012) as individuals may have an incentive to overplay their own health problems for the purpose of gaining disability benefits. Finally, an important advantage of our analyses is that they are carried out in a very interesting yet homogeneous setting, such as the Danish one. Denmark has rising disability-related exit, universal health care access and coverage and generous health benefits provision. Thus, any socioeconomic gradient in health in Denmark cannot be due to differential access, allowing for cleaner identification of the effects of education and occupation on health-related exit from the labor market.

\footnotetext{
${ }^{3}$ In a sensitivity analysis, we try an alternative measure of physical demands using the Danish Work Environment Cohort Study (DWECS) data which has less detailed skill measures compared to the DOT.
} 
The comprehensiveness of the Danish register data enable us to estimate a recursive model of work incapacity, education and occupation with correlated cross-equation errors and unobserved heterogeneity. Our findings indicate that education generally reduces sickness absence, although more strongly for men than women. At the same time, we find an independent role for occupation, which also differs by gender. More specifically, a stronger causal effect increasing temporary work incapacity is seen for women than men, despite the average probability of sickness absence being fairly similar by gender. The effects of education and occupation on permanent work incapacity or disability, on the other hand, are generally insignificant. These results may be relevant for countries with similar institutions to the Danish case, and can inform policy in these cases of the ways in which to stem the inflow into sickness absence and disability, respectively, temporary and permanent incapacity.

The paper is organised as follows. Section 2 introduces the data set and presents main descriptive statistics. Section 3 provides details on the empirical strategy. Section 4 explains the results of our empirical analysis, Section 5 presents the findings from the sensitivity analysis and Section 6 concludes. 


\section{Data}

\subsection{Data description}

We begin with the population of individuals from 1998 to 2002. Individuals selected for the sample are required to be employed at least in 1997 and are born in Denmark between 1943 and 1950, which are cohorts a few years prior to and after the school reform, that we use for our identification strategy. ${ }^{4}$ Data is taken from administrative registers from Statistics Denmark. It is sourced from the Integrated Database for Labor Market Research (IDA) and includes characteristics for individuals such as highest educational attainment, marital status, and occupation for each year. Work incapacity data comes from another admistrative dataset, DREAM (Danish Register-based Evaluation of Marginalisation), which contains information on weekly receipts of all social transfer payments for all citizens in Denmark since 1991, and seperately records sickness absence since 1998 .

Temporary work incapacity (TWI) is defined as sickness absence for more than eight consecutive weeks. ${ }^{5}$ This threshold is chosen as municipalities in Denmark are

\footnotetext{
${ }^{4} \mathrm{~A}$ general reform in 1958 abolished a division of schooling that occurred after the 5th grade and affected attendance particularly beyond the 7 th grade, i.e. beyond primary school. The reform also eliminated a distinction between rural and urban elementary schools wherein only urban schools could offer classes from 8th to 10th grades. The impact of the reform on individuals is based on their year and area of birth (on the parish level). Whether the area had an urban or rural school is specified in the same way as in Arendt (2008). Measuring the effect on beyond primary education exploits changes in the rural-urban difference from before to after the reform. More details about the 1958 reform are reported in the next section.

${ }^{5}$ Workers can receive the benefit for up to 52 weeks, but the benefit period may be extended under certain circumstances, e.g. if the worker has an ongoing workers' compensation or disability benefit claim. Employers finance their workers' sickness benefits for the first three weeks, and public authorities finance the remaining period.
} 
obliged to follow up all cases of sickness benefit within eight weeks after the first day of work incapacity, and aligns with other studies using Danish register data (Christensen et al. (2008), Lund et al. (2006)) and combined survey-register data (Høgelund and Holm (2006) and Høgelund et al. (2010)). ${ }^{6}$ If return to ordinary work is impossible because of permanently reduced working capacity, the municipality may refer the sicklisted worker to a wage-subsidized job, the latter being wage-subsidized jobs with tasks accommodated to the worker's working capacity and with reduced working hours. Depending on the reduction of the worker's working capacity, the wage subsidy equals either one half or two-thirds of the minimum wage as stipulated in the relevant collective agreement. If a person with permanently reduced working capacity is incapable of working in a wage-subsidized job, the municipality may award a permanent disability benefit, which is financed entirely by public authorities.

The first model, of TWI, uses the entire population of Danish workers who meet the selection criteria stated earlier. The second model uses the full sample of individuals who experience TWI. It considers permanent work incapacity as the receipt of disability benefit or the transit to wage-subsidized jobs, and uses data for welfare and employment status following TWI, which is also taken from the DREAM register. We consider the longest spell in the 24 weeks following TWI as the destination status. The latter is grouped into four categories: permanent work incapacity, self-sufficiency,

\footnotetext{
${ }^{6}$ After the first eight weeks of sickness, the municipality must perform a follow-up assessment every fourth week in complicated cases and every eighth week in uncomplicated cases. The primary goal of the assessments is to restore the sick-listed worker's labor market attachment. The assessments must take place in cooperation with the sick-listed worker and other relevant agents, such as the employer and medical experts.
} 
early retirement and other welfare receipts (see Table 1). Permanent work incapacity (PWI) includes disability benefits and wage-subsidized jobs while self-sufficiency is largely full-time employment. $68 \%$ of the sample goes back to ordinary work after experiencing temporary work incapacity and a considerable share $(22 \%)$ transit to a status of permanent work incapacity.

As a measure of education, we use a binary variable denoting education beyond primary schooling (greater than 8 registered years of education). Whether or not an individual has a physically demanding job is proxied by an occupational brawn score, which we construct from the individual's contemporaneous occupation codes linked to detailed job characteristics from the U.S. Dictionary of Occupational Titles (DOT). The fourth edition (1977) of the DOT provides measures of job content, reporting 38 job characteristics for over 12,000 occupations. Rendall (2010) performs factor analysis on the 38 job characteristics in DOT, taken across occupations and employment from the US 1970 census. Following Ingram (2006), Rendall arrives at 3 factors, which are labelled brain, brawn, and motor coordination. ${ }^{7}$ We use the results of factor analysis by Rendall (2010) on these characteristics, and obtain a single measure of brawn for each occupational code provided in the Danish register set.

We then use crosswalks to match census occupation codes to the Danish register's

\footnotetext{
${ }^{7}$ The orthogonal factor analysis results in three factors explaining 93 percent of the total covariance. A partition of job characteristics into the three factors is chosen, according to high coefficients from the analysis. This partition is then used to construct a second factor analysis that allows for correlation across factors. We sum the scores on the six variables contributing to the brawn factor, weighted by the coefficients from factor loading, so that for each 1970 census occupation, we obtain a single value denoting brawn level. For more details about the factor loadings, see Table 2.
} 
occupation codes, called DISCO (Danish ISCO - International Standard Classification of Occupations). ICPSR has used the Treiman file to map from DOT to 1970 and 1980 census occupation codes. Each 1980 census occupation code in the Treiman file carries a vector of DOT scores, which is, where applicable, an average over the 1970 codes' scores. We use a crosswalk of 506 occupations at Ganzeboom (2003) to map 1980 census codes to ISCO-88. The 4-digit ISCO code is organised hierarchically in four levels and is almost identical to DISCO (390 vs. 372 codes). ${ }^{8}$ The first digit aligns broadly with the education level required for the job, and the job classification becomes more detailed with the second and third digits. If a direct match from a DISCO code to 1980 census code is not found, we use the nearest category, above or immediately adjacent (based on preceding digits). One-to-many matches receive an average of the brawn score. Over $92 \%$ of workers have an occupation code to which a brawn score can be attributed.

We proceed with two alternative measures of physical demands of the job. One is related only to the brawn level of the current job being above the 75 th percentile of the gender specific brawn distribution while the other is based on having a history of brawny work in the last three years.

\footnotetext{
${ }^{8}$ http://www.dst.dk/Vejviser/Portal/loen/DISCO/DISCO-88/Introduktion.aspx
} 


\subsection{Variables and Descriptive Statistics}

The full sample consists of 2.3 million individuals born between 1943 and 1950, employed in 1997, and subsequently observed in 1998-2002. Table 3 presents descriptive statistics for the full sample split by gender, and within gender group, separately for all and for the higher of the two educational groups (above primary level). Means are taken over all person years 1998-2002 when workers are between 48 and 59 years of age. 1998 is selected as the first year because reliable information on sickness spells is only available starting from that point on. Prior to this, sickness spells are indistinguishable from maternity leave spells for women. Furthermore, because we are concerned about encountering major changes in the disability policy scheme in 2003, 2002 is the last allowable year in the sample period.

Around 3\% of women and men aged 48-59 experience TWI. For those with education beyond primary level, the corresponding shares are on average slightly lower. Years of education are, by definition, lower for all workers compared to educated workers, almost 10 years vs. 12 years. Women and men in the full sample are similar in terms of age, the average being 53 years. Looking at the shares of workers employed in physically demanding occupations, a striking gender difference is seen, no matter their age (see also Figure 2). While $12 \%$ of women work in such occupations, $25 \%$ percent of all men (even $13 \%$ of men with more than primary education) work in brawny jobs, reflecting the high degree of occupational segregation by gender into, respectively, blue-collar (male) and white-collar (female) occupations in the Danish labor market. 
Moreover, the average brawn level in women's commuting areas (see footnote 5) is also considerably lower, 67, compared to 98 for men. Marriage rates among older working women are about 2 percentage points lower than among their male counterparts. Educated workers -both women and men-are more likely to be born in a city. The next row in the table indirectly provides the proportion affected by the education reform instrument, by gender and education. As approximately $26 \%$ of individuals are born in a city after the reform year, $74 \%$ of our sample is affected by the reform. Due to mortality risk increasing with age, there is slightly more representation of the younger cohorts in the sample, however, differences in cohort sizes are not large.

When conditioning on TWI in Table 4, 21-23\% of women and 19-21\% of men are on PWI, so the differences are not large. The TWI sample is also less educated than the full sample but is about the same age. Those on TWI are more likely to work in brawny jobs than those in the full sample. The brawniness of their (the TWI) commuting area is, however, similar to that of all workers. They are also less likely to be married compared to the full worker sample, perhaps indicative of the health benefits that can be obtained from marriage (Wilson and Owsald, 2005). Means of the remaining factors in this table (born in city, reform*born in city, cohort dummies) appear to be largely the same for the TWI sub-sample as for the full sample. 


\section{Empirical strategy}

Our point of departure for describing the determinants of either TWI or PWI is a set of modified versions of Grossman's intertemporal model of health (Muurinen, 1982; Muurinen and Le Grand, 1985; Case and Deaton, 2005). According to this theoretical setup, utility maximization determines the optimal level of health inputs and yields a reduced form model of the demand of health, such as:

$$
H_{i t}=X_{i t} \beta+\gamma_{1} E_{i}+\gamma_{2} P J_{i t}+\xi_{i t}
$$

where $H_{i t}$ is the health stock of individual $i$ at time $t, X_{i t}$ include a number of exogenous regressors in the health equation, $E_{i}$ is education, $P J_{i t}$ is having a physically demanding job and $\xi_{i t}$ is an error term, consisting of a time invariant $v_{i}$ and an idiosyncratic component $u_{i t}$. Education may be correlated with the unobserved component as those with better "endowment" obtain more education and are at the same time more healthy as adults (Card, 1999; Rosenzweig and Schultz, 1983). Alternatively a correlation between education and $\xi_{i t}$ may stem from the assumption that individuals with higher preferences for the future are more likely to engage in activities with current costs and future benefits such as education and health investments (Fuchs, 1982; Grossman and Kæstner, 1997). To take account of this endogeneity issue, we assume that education ${ }^{9}$ and the health outcome, $W I_{i t}$ (work incapacity), in our case

\footnotetext{
${ }^{9}$ Education is measured by a dummy variable taking value of one for those having any education beyond primary schooling, as explained in the previous section.
} 
the probability of either TWI or PWI, are related through the following equations:

$$
\left\{\begin{array}{l}
W I_{i t}=X_{1 i t} \beta_{1}+\gamma_{1} E_{i}+\gamma_{2} P J_{i t}+v_{1 i}+u_{i t} \\
E_{i}=X_{2 i} \beta_{2}+\phi_{1} U R B_{i}+\phi_{2}\left(U R B_{i} * R E F_{i}\right)+v_{2 i}+\eta_{i}
\end{array}\right.
$$

where $v_{1 i}$ is the time invariant unobserved component correlated with $v_{2 i}$ but uncorrelated with $X_{1 i t}$, which include age, age squared, gender ${ }^{10}$, whether married and born in a urban area, the average work incapacity (TWI or PWI) annual growth rate for each level of brawn, cohort and region of living dummies. Education is instead a function of cohort dummies and whether born in a urban area $\left(U R B_{i}\right)$ and whether affected by the 1958 school reform $\left(R E F_{i}\right)$. As in Arendt $(2005,2008)$, the interaction of the urban and reform dummies constitute our exclusion restrictions. That is, the change in urban-rural differences in education due to the 1958 reform is exploited to identify the education effect on work incapacity. We contend that the exogenous variation in education is stronger than what is visible in the population from the number of years of education registered (see Figure 1), for two reasons. Prior to the reform, schooling in the 6th and 7th grades was determined on the basis of a test conducted at the end of 5th grade. This would have led to a different schooling experience between two sets of students in the same cohort, even when both are registered with 7 years of education. Plus in rural schools before the reform, the curriculum level and the number of lessons were lower. These differences were abolished in 1958, which we use

\footnotetext{
${ }^{10}$ To allow the effects of education and occupation to be gender specific, we will provide estimation results separately for women and men.
} 
to identify causal effects of increasing years of education, as well as of potentially increasing quality of education, for individuals born in rural areas and from 1946 onwards.

We apply a quasi-maximum-likelihood estimator with discrete factor approximations (Mroz, 1999; Picone et al., 2003; Arendt, 2008) to estimate equation (2). The advantages of this approach are twofold. On one hand, it is particularly suited to correct for endogeneity and selection bias caused by unmeasured explanatory variables in dichotomous dependent-variable models (Cameron and Taber, 1998). On the other, it avoids the need to evaluate multivariate normal integrals and it is less expensive computationally. Moreover many economists have criticized IV two-stage methods (Vuong, 1984) arguing that they may deliver consistent parameter estimates with high standard errors, making the estimates very unreliable. According to Mroz, the discrete factor method compares favourably with efficient estimators in terms of precision and bias. He demonstrates that the discrete factor method outperforms 2SLS in the presence of weak instruments. Also, Staiger and Stock (1997) showed that two step approaches are highly dependent on the quality of instruments.

To implement this estimation method, the following recursive model of work incapacity (WI) and education (E) with correlated errors is considered:

$$
\left\{\begin{array}{l}
W I_{i t}=f\left(X_{1 i t} \beta_{1}+\gamma_{1} E_{i}+\gamma_{2} P J_{i t}+v_{1 k}+u_{i t}\right) \\
E_{i}=g\left(X_{2 i} \beta_{2}+\phi_{1} U R B_{i}+\phi_{2}\left(U R B_{i} * R E F_{i}\right)+v_{2 k}+\eta_{i}\right)
\end{array}\right.
$$


where $u_{i t}, \eta_{i}$ are independently distributed and $v_{1 k}$ and $v_{2 k}$ represent the random components. The latter are assumed to follow a discrete distribution $p_{k}$, where $p_{k} \geq 0$ for $k=1, \ldots, K$ and $\sum_{k=1}^{K} p_{k}=1$. The identification of the education effect is obtained by the non linearity of the $f($.$) and g($.$) functions, but it is strengthened using an$ exclusion restriction. With education being binomial, the contribution to the likelihood of a given individual is given by:

$$
P\left(W I_{i t}=w i_{i t}, E_{i}=e_{i}\right)=\sum_{k=1}^{K} p_{k} P\left(W I_{i t}=w i_{i t} \mid v_{1 k}\right) P\left(E_{i}=e_{i} \mid v_{2 k}\right)
$$

Because the number of points $\mathrm{K}$ are unknown and there can be many local maxima, it is important to look for good starting values. We use single equation Probit estimates and add one point of support for the mixing distribution at a time, doing a grid search for the new point. We added up to three points of support. Unfortunately, there is no standard theory indicating how to select $\mathrm{K}$ in a finite sample. Following Cameron and Taber (1998) and Heckman and Singer (1984), we add additional points of support until the likelihood fails to improve.

The previous recursive model is then extended to also tease out the causal impact of a physically demanding job (PJ): 


$$
\left\{\begin{array}{l}
W I_{i t}=f\left(X_{1 i t} \beta_{1}+\gamma_{1} E_{i}+\gamma_{2} P J_{i t}+v_{1 k}+u_{i t}\right) \\
E_{i}=g\left(X_{2 i} \beta_{2}+\phi_{1} U R B_{i}+\phi_{2}\left(U R B_{i} * R E F_{i}\right)+v_{2 k}+\eta_{i}\right) \\
P J_{i t}=h\left(X_{3 i t} \beta_{3}+\delta_{1} E_{i}+\delta_{2} B R A W N_{-} A V E_{i}+v_{3 k}+\mu_{i t}\right)
\end{array}\right.
$$

where $X_{3 i t}$ includes age, age squared and marital status. As before, the identification of the occupation effect is obtained by the non linearity of the functions, but it is strengthened using an exclusion restriction. As an instrument for having a physically demanding job, we use the 1994 average brawn (separately for male and female) of all employed individuals in the current "commuting area". ${ }^{11}$ The average brawn at the commuting area level presents a suitable supply driven instrument for the individual decision to select a brawny job herself which is not correlated with the risk of work incapacity. This argument is further reinforced by the role of networks in the employment process (Montgomery, 1991, Munshi, 2003). Thus individuals placed in areas with high average brawn are also more likely to have a physically demanding job. Furthermore, it is important to emphasize that although the commuting areas are not closed economies in the sense that workers are free to move out, there is a clear evidence of low residential mobility for Denmark (Deding et al. 2009), which seems to support the appropriaterness of our IV strategy. In theory, it may be preferable to use as instrument the brawn level of the commuting area when the individuals made their first

\footnotetext{
${ }^{11}$ The so-called functional economic regions or commuting areas are identified by using a specific algorithm based on the following two criteria. Firstly, a group of municipalities constitute a commuting area if the commuting within the group of municipalities is high compared to the interaction with other areas. Secondly, at least one municipality in the area must be a center, i.e. a certain share of the employees living in the municipality must work in the municipality, too (Andersen A. K., 2000). In total 51 commuting areas are identified.
} 
job decisions, say at ages 20-25. Unfortunately, the DISCO occupational code used to identify the commuting area average brawn is only available from 1994 onwards, meaning that we cannot go back earlier than that for the purpose of constructing the instrument. Furthermore, the Danish Economic Council (2002) reports that despite low geographic mobility, the job turnover rate is quite high in Demark which means that a significant share of individuals would have changed their jobs. Table 2 shows the distribution of average brawn across commuting areas by gender. At the median, the average brawn of males' commuting areas is $45 \%$ greater than the average brawn of females' commuting areas. ${ }^{12}$

\section{Results}

\subsection{Results for temporary work incapacity}

We begin by exploring the effects of education and working in a physically demanding job on temporary work incapacity. In Tables 5-6, the dependent variable is temporary work incapacity (TWI), i.e., the probability of having a sickness spell of at least 8 weeks, for, respectively, women and men. Coefficient estimates from the quasi-ML model with discrete factor approximation are shown together with standard errors. For education and physically demanding job, we also report the calculated marginal effects, in parentheses below. Six models (columns) are discussed in this section, while

\footnotetext{
${ }^{12}$ The correlation between having had a brawny job in the past three years and the average brawn in the commuting area is $14 \%$ for males and $9.5 \%$ for females. The correlation between the current brawn of individual occupation and the average brawn in the commuting area is $15 \%$ for males and $13 \%$ for females.
} 
the seventh is taken up in Section 5: Model 1 where both education and occupation are treated as exogenous and time-invariant unobserved heterogeneity is not accounted for, Model 2 the same as Model 1 but accounting for unobserved heterogeneity, Model 3 which is the same as Model 2 except that the endogeneity of education is modeled, Model 4 the same as Model 2 but where working in a physically demanding occupation is treated as endogenous, Model 5 in which both education and occupation are endogenously determined, and finally, Model 6 which is the same as Model 5 but where an alternate definition of occupation reflecting a past history of working in a physically demanding job is applied in place of a current brawny occupation i.e., observed working in a physically demanding job in the last 3 years. As clarified in the previous section, to minimize other sources of potential endogeneity, we include only few covariates in the specification of the main equation: age, marital status, born in a city, the average work incapacity annual growth rate for each level of brawn, 7 cohort dummies and 14 regional dummies.

The results for women, in Table 5, are discussed first. Model 1 shows that education exceeding primary school level reduces their likelihood of TWI significantly by 1.4pp. Working in a physically demanding job, as expected, increases the likelihood of females going on TWI by $1.8 \mathrm{pp}$, and this effect is also statistically significant. Accounting for time-invariant unobserved heterogeneity in Model 2 hardly changes the results and produces, if anything, even larger effects of education and occupation on TWI. 
In Model 3, when instrumenting education by the urban-rural difference in education following the 1958 school reform, we see that the instrument is significantly related to the education measure at the $5 \%$ level and shows, as expected, that the urban-rural difference in the share attaining education beyond primary level decreased after the reform. However, the effect of education on reducing TWI likelihood now becomes statistically insignificant. The effect of a physically demanding job remains significant with the same marginal effect. In Model 4, current occupation is instrumented by the (lagged) average brawn in a worker's commuting area while education is treated as exogenous to TWI. The average brawn is positively related to the brawniness of a female worker's job and is highly significant, i.e. at the $1 \%$ level. Instrumenting occupation, as can be expected, reduces its effect on TWI and in fact, it is no longer statistically significant.

In Model 5, both education and occupation are simultaneously instrumented for and the results show that education (occupation) reduces (increases) the probability of experiencing TWI and the impacts remain statistically significant. More specifically, education exceeding primary school level reduces the likelihood of TWI by $0.5 p p$ while working in a physically demanding job increases the same likelihood by $1.2 \mathrm{pp}$. These marginal effects are equivalent to a decrease and a rise in the probability of TWI by 16 and 38 per cent, respectively. ${ }^{13}$ Interestingly, when computed separately by age, we also find that the marginal effect of having a physically demanding job monotonically

\footnotetext{
${ }^{13}$ The figures are obtained using the average probability of TWI. From the estimates in Table 5, the average probability of TWI is approximately 3 per cent. Therefore, the changes in the probability of TWI, in percentage terms, are $(-0.005 / 0.032) * 100=-15.625$ and $(0.012 / 0.032)^{*} 100=37.5$, respectively.
} 
increases with age (except for a flattening off between ages 52 and 55), as shown in Figure 4, confirming the "broken down by work" hypothesis formulated in Case and Deaton (2005).

What if it is not the brawniness of the current occupation but rather having a history of brawny jobs that matters for TWI? Workers approaching the end of their careers, particularly those experiencing health deterioration, may switch to softer "bridge" jobs or partial retirement before retiring that may even be outside the occupation of the career job (Ruhm, 1990). This would imply that the physical demands of the job are erroneously proxied by current occupation brawn. However, when applying the history-based measure of the physical demands of the job (having a brawny job in the last three years) in Model 6, it can be seen that occupation still has a causal effect on females' probability of TWI, and that the marginal effect decreases slightly to 0.8pp. Thus for women, the attributes of the current job matter more for sickness absence than a history of physically demanding work. Presumably, this result shows that bridge jobs are not as important a mechanism in high-wage, high labor-cost regimes where it may be more difficult for older workers to switch jobs at the end of their careers and/or the incentives to do so may be lower. Furthermore, Danish workplaces are said to be among the most accommodating in the world, and the possibility to decrease work hours or negotiate more flexible conditions would be tried before switching employment. Education remains significant in this specification. 
Moving to the results of the effect of education and occupation on TWI for men, in Table 6 we see in Model 1 that the effect of working in a physically demanding occupation is slightly smaller than it is for women, increasing the chances of TWI by 0.9pp. Similar to women, education beyond primary decreases men's likelihood of TWI by $1.4 \mathrm{pp}$. As in the case for women, accounting for time-invariant unobserved heterogeneity does not change the results substantially. When instrumenting education in Model 3, the effect of education on TWI is reduced in size and the exclusion restriction is significant and negative as we would expect. In Model 4, where occupation is endogenized and instrumented by the (lagged) average brawn in a worker's commuting area, the instrument is significant at the $1 \%$ level. Interestingly, the effect of occupation remains significant once it is modeled as endogenous.

Proceeding to the most general specification in which both education and occupation are modeled as endogenous in Model 5, we find that both education and occupation are statistically significant. Education exceeding primary school level reduces the likelihood of TWI by 1pp, while working in a physically demanding occupation has a marginal effect, which is a little more than half as large as the effect for women, 0.7pp compared to 1pp. However, relative to the mean, these figures are equivalent to a decrease and a rise in the probability of TWI by 37 and 26 per cent, respectively. ${ }^{14}$ As in the case for women, the impact of occupation magnifies with age, as clearly indicated in Figure 8, however, the incline is not as steep. Trying out the alternative definition of

\footnotetext{
${ }^{14}$ From the estimates in Table 7 , the average probability of TWI is 2.7 per cent. Therefore, the changes in the probability of TWI, in percentage terms, are $(-0.010 / 0.027) * 100=-37$ and $(0.007 / 0.027) * 100=25.9$, respectively.
} 
occupation based on history of physically demanding work does not change the results for men: education remains negative and significant and occupation exerts a statistically significant effect on increasing TWI with a marginal effect of $0.5 \mathrm{pp}$.

Finally, for both men and women, in Model 6, the covariances between education and TWI is estimated to be negative (i.e. the unobserved factors affecting a greater tendency to go on TWI vary negatively with the unobserved factors affecting more education), the covariance between working in a physically demanding job and TWI is positive and the covariance between education and physically demanding job is negative, as may be expected. The negative (positive) correlation between TWI and education (physically demanding job) could reflect the impact of unobservables such as moral hazard behavior that was mentioned earlier.

\subsection{Results for permanent work incapacity}

To probe further the effects of occupation and education on work incapacity, in Tables 7 and 8 we estimate their impact on the probability of PWI (either the receipt of disability benefits or the transit to non-regular subsidized jobs) conditional on TWI, hence the lower sample sizes. Here too, the same six models are estimated for, respectively, women and men. As was the case for TWI, the same parsimonius specification is chosen for the equation for PWI. Besides education and occupation (and their instruments), only age and its square, marital status and residence in an urban area are included as determinants. Although in principle PWI and TWI could be separate 
processes with each their own determinants, we retain a sparse set of common determinants for both mainly because our focus is on uncovering the relationships between education, occupation and the relevant measure of work incapacity controlling for the most obvious sources of heterogeneity and not on accounting for all the variation in the measure of work incapacity. While the latter is certainly a worthwhile approach, it would introduce many potentially endogenous determinants which further complicates the analysis, given that we already are handling two sources of endogeneity simultaneously.

Comparing the results for women in Table 7 to Table 5, we see that in Model 1 , the estimated effect of education is stronger when the outcome is permanent work incapacity, 4.4pp compared to 1.4pp. However, similarly to TWI, working in a physically demanding job increases this probability by 1pp. When endogenizing education and occupation simultaneously, their effects lose significance, in spite of significant and correctly signed instruments. The effect of occupation is not statistically significant even in the specification based on the occupational history. ${ }^{15}$ As in Andren (2011), we also estimate the most general specification by distinguishing between the probability of "full time" work disability, i.e. the receipt of disability benefits, and the probability of part-time "work disability", i.e. working as subsidized worker at reduced working hours. The results are reported in columns 7 and 8 of Table 7 and hardly change compared to the previous ones. Very similar results are found for men in Table 8, as

\footnotetext{
${ }^{15}$ Results not reported in this paper show that the impact of occupation does not even vary with age. These additional calculations are available on request from the authors.
} 
the causal impact of both education and occupation are not precisely estimated.

For both men and women, in Tables 7 and 8, the cross-equation correlations between education and PWI are estimated to be negative (i.e. the unobserved factors affecting a greater tendency to go on PWI vary negatively with the unobserved factors affecting more education) and the covariance between working in a physically demanding job and PWI is positive. As earlier mentioned, a possible explanation for these plausible correlations could be, controlling for other things, that educated people and individuals working in non-manual jobs have lower expected replacement rates from disability insurance and, therefore, would be less prone to compensation-seeking behaviour.

\section{Sensitivity}

The results imply a significant role for our novel measure of a physically demanding job, so we test the sensitivity of results to this measure. To this end, we run the model using an alternative measure of brawny job based on responses to the Danish Work Environment Cohort Study (DWECS). An index is constructed from principal components analysis (PCA) on a subset of the workplace questions in the survey conducted in 2005.16

DWECS is a panel study to monitor the working population for the prevalence of occupational risk factors. The study conducted phone interviews on physical, thermo-

\footnotetext{
${ }^{16}$ We use the 2005 survey as it includes two questions on physical exertion, where earlier surveys do not.
} 
chemical and psychosocial exposures, health and symptoms, including a doctor's diagnosis, as well as self and peer assessment. It is a representative sample of the Danish labor force. Details of the sampling are in (Burr et al., 2003, 2006). The purpose of the DWECS survey is not to derive a complete description of the job or activities, so it is not appropriate to use factor analysis on the entire questionnaire, as variation driven by any factor accounts for too little of the total variation. Instead, we first select questions about more intrinsic (objective) aspects of the job (rather than of the workplace, or of the manager and colleagues), and these include all questions about physical activity in the workplace. They also include aspects of job control and autonomy, and mental or emotional demands. The first principal component accounts for almost 30 percent of the variation, whose eigenvector reflects a brawn- like dimension. Although it is driven by variation of jobs in relation to other jobs, rather than by fundamental tasks or analysis of the composition of a job, it appears that the most objective questions in the survey highlight variation in brawniness as the main dimension along which to discriminate occupations. ${ }^{17}$

Results obtained using this alternative measure of brawny job are reported in the last columns of Tables 5-8. In line with the main results, we find that women (men) working in a physically demanding job have a $1.3(0.7)$ percentage points higher likeli-

\footnotetext{
${ }^{17}$ The eigenvector corresponding to the first principal component is used to score each occupation for brawn. The 61 elements in the eigenvector, each corresponding to a survey question, are the loadings given to each survey question. As most of the questions have ordered multiple choice (5 or 2) answers, we use the polychoricpca package in Stata (Kolenikov and Angeles, 2009) to derive principal components from the 105 occupations for which there were at least 10 respondents. If a direct match from an occupation to a DISCO code from the full sample is not found, we use the nearest category. For each individual in the full sample, the instrument of commuting area level brawn based on the new index is generated in the same way as for the DOT-based index.
} 
hood of TWI than otherwise comparable women (men). ${ }^{18}$ Furthermore, for both women and men, the effects on the probability of PWI are imprecisely estimated, as we have previously found in section 4, exploiting the DOT-based brawn index.

\section{Conclusion}

Large numbers of working age individuals continue to leave the labor force via disability pension enroute sickness absence in almost all OECD countries today and the lost work effort of these individuals constitute a great cost to these economies. The objective of this paper is to empirically model the relationships between education, working in a physically demanding job and health-related exit from the labor market with a view to determining whether these factors have causal impacts on sickness absence and the inflow to disability and their relative importance for each of these processes.

Theoretically, education can impact health and disability through various channels, and one of these could be the nature of jobs. For this reason, we estimate a recursive model of work incapacity and education and occupation with correlated cross-equation errors and unobserved heterogeneity on comprehensive Danish longitudinal data. These data contain objective register-based sickness absence and disability spells, unlike selfreported measures used in the previous literature. The empirical model simultaneously allows for endogenous education and occupation and identification is achieved by ap-

\footnotetext{
${ }^{18}$ From the estimates in Table 7 and 8 , the average probability of PWI is approximately 22 per cent for both women and men. Therefore, the changes in the probability of TWI, in percentage terms, are respectively $(0.013 / 0.23) * 100=5.65$ and $(0.007 / 0.23) * 100=3.04$, respectively.
} 
plying as exclusion restrictions a carefully constructed measure of the physical demands of the occupations at the commuting area level and the exogenous variation induced by a major educational reform.

Our findings show that education (physically demanding occupation) generally reduces (increases) temporary work incapacity only, as the effects on permanent work incapacity are not precisely estimated. For both men and women, education exceeding primary school level decreases the probability of TWI, but more so for men than women (37 versus 16 per cent). As this effect arises net of occupation, it suggests that the extra education benefits men more, via more health knowledge, changed time rate of preferences or greater efficiency in health investments. This is similar to the finding in Kemptner et al. (2011) who also find that changes in compulsory schooling laws over a 20-year period in West Germany mainly reduce the probability of long-term illness for men but not for women. ${ }^{19}$

At the same time, we find an independent role for occupation, which also differs by gender. More specifically, a stronger causal effect increasing temporary work incapacity is seen for women than men (38 versus 26 per cent), despite the average probability of TWI being fairly similar by gender. We also uncover evidence of workers in physically demanding jobs, both men and women, being "broken down by work" over time, and

\footnotetext{
${ }^{19}$ In earlier work, Datta Gupta and Bengtsson (2012) find, using two-stage least square methods, that the educational reform significantly reduces both men and women's disability exit, in a specification which does not control for job characteristics. Thus, they do not model the endogeneity of occupation and nor do they estimate separate exits via sickness absence and disability.
} 
women more so than men, even though the average brawn level of men's jobs was significantly higher. A number of explanations could be offered for the stronger effect of a physically demanding occupation on women's transit to sickness absence such as biological differences in the perception of pain, a greater socialization of men to "tolerate" declining health and remain in the workforce or a higher degree of employer accommodation in men's jobs. Future work could look into which of these potential explanations carry merit.

Our second major finding is that neither education nor the brawniness of the occupation has any effect on disability benefit receipt. One explanation could be that conditional on being on sickness absence, disability decisions are based on strict health and not social criteria in Denmark. However, the fact that in 2003 the programme was reformed and the awards criteria made stricter testify perhaps to a certain laxity in the awards system in the period before 2003, which we study. Another mechanism could be the rise in the share of awards based on mental disorders over this period, going from $32.1 \%$ of all grants in 2001 to $44.4 \%$ in 2006 and a decline in the share of grants based on musculo-skeletal disorders implying a decreasing role for occupational brawn. Recall that the factor analysis based on DWECS data included questions relating to job control and autonomy, and mental or emotional demands in addition to physical demands. However, occupations distinguished themselves most from each other in the DWECS according to a brawn-like aspect. A remaining explanation for the lack of an effect of brawn on permanent work incapacity could be greater workplace accommo- 
dation and efforts to retain workers in Danish workplaces. Finally, several robustness checks on the definition of work incapacity and physically demanding job confirmed the results above. 


\section{References}

[1] Andersen, Anne K., 2000. "Commuting Areas in Denmark", Copenhagen, AKF forlaget.

[2] Arendt, J. N., 2008. "In Sickness and in Health- Till Education do us Part: Education Effects on Hospitalization", The Economics of Education Review, 27(2): 161-172.

[3] Andren, D., 2011. "Half empty of half full: The importance of the definition of part-time sick leave when estimating its effects", Orebro University working paper, $4 / 2011$.

[4] Autor, D. H., and Duggan M.G., 2006. "The Growth in the Social Security Disability Rolls: A Fiscal Crisis Unfolding", Journal of Economic Perspectives 20(3): 71-96.

[5] Bago d'Uva, T., van Doorslaer, E., Lindeboom, M. and O Donnell, O. 2007. "Does reporting heterogeneity bias the measurement of health disparities?", Health Economics, 17.

[6] Becker, G. S. and C.B. Mulligan, 1997. "The Endogenous Determination of Time Preference", Quarterly Journal of Economics, 112: 729-758.

[7] Bengtsson, S. Report on the Employment of Disabled Persons in European Countries, Country: Denmark. The Academic Network of European Disability Experts (ANED) 2007; VT/2007/005 
[8] Bolduc, D., Fortin B., Labrecque F., and Lanoie P., 2002. "Workers' Compensation, Moral Hazard and Composition of Workplace Injuries", Journal of Human Resources 37(3):623-652.

[9] Burr H, Bjorner JB, Kristensen TS, et al., 2003. "Trends in the Danish work environment in 1990-2000 and their associations with labor-force changes", Scand J Work Environ Health 29.

[10] Burr, H., Bach, E., Gram, H. and Villadsen, E., 2006. "Arbejdsmiljo i Danmark 2005 - et overblik fra den Nationale Arbejdsmiljøkohorte", Kobenhavn, Arbejdsmiljø instituttet http://www.arbejdsmiljoforskning.dk/ / media/Arbejdsmiljoedata/NAK/nak2005arbejdsmiljoe.pdf

[11] Cameron, S. and C. Taber, 1998. "Discount Rate Bias in the Returns to Schooling", Nothwestern U

[12] Card, D., 1999. "Causal effects of education on earnings". Handbook of labor economics 3 A: 1801-1863.

[13] Case, A. and Deaton, A., 2005. "Broken Down by Work and Sex: How Our Health Declines", in David A. Wise, editor, "Analyses in the Economics of Aging" University of Chicago Press.

[14] Christensen KB, Labriola M, Kivimaki M, Lund T., 2008. "Explaining the social gradient in long-term sickness absence: a prospective study of Danish employees", J Epidemiol Community Health. 62 . 
[15] Cutler, D.M. and Lleras-Muney, A., 2006. "Education and Health: Evaluating Theories and Evidence", NBER Working Paper, no. 12352.

[16] Cutler, D.M. and Lleras-Muney, A., 2007. "The Education Gradient in Old-age Disability", NBER forthcoming chapter in the Research Findings in the Economics of Aging.

[17] Datta Gupta, N. and Bengtsson, S. "The Stronger Sex? The Effect of Compulsory Schooling Reforms on Gender Differences in Disability Exit", mimeo, University of Aarhus.

[18] Deding, M., Filges, T. and Jos Van Ommeren, 2009. "Spatial Mobility and Commuting: the Case of Two-Earner Households", Journal of Regional Science 49: $113-47$.

[19] Deding, M. and Filges, T., 2009. "Danske lønmodtagers arbejdstid - En registeranalyse baseret på lønstatistikken (Working hours of Danish Employees - A Register Analysis based on the Wage Statistics)", SFI Working Paper, 09-03.

[20] Fletcher, J. M., Sindelarn J., and Yamaguchi S., (Forthcoming). "Cumulative effects of job characteristics on health", Health Economics.

[21] Freedman, V.A. and Martin, L.G., 1999. "The Role of Education in Explaining and Forecasting Trends in Functional Limitations among Older Americans", Demography, 36(4):461-473. 
[22] Fried, L.P. and Guralnik, J.M., 1997. "Disability and Older Adults: Evidence regarding Significance, Etiology and Risk". Journal of American Geriatric Society, 45:92-100.

[23] Fuchs, V., 1982. "Time Preference and Health: An Exploratory Study". In Fuchs (ed.) Economic Aspects of Health: Second NBER Conference in Standford. University of Chicago Press, Chicago, 93-119.

[24] Ganzeboom, Harry B.G.; Treiman, Donald J., 2003. "International Stratification and Mobility File: Conversion Tools", http://home.fsw.vu.nl/hbg.ganzeboom/ismf/occisko. (26.2.03)

[25] Goldman, D.P. and Lakdawalla, D., 2001. "Understanding Health Disparities across Education Groups", NBER Working Paper, no. 8328.

[26] Grossman, M., 1972. "On the Concept of Health Capital and the Demand for Health", Journal of Political Economy 80(2): 223-255

[27] Grossman, M., and Kæstner, R., 1997. "The Effects of Education on Health", The Social Benefits of Education, MI: 69-123.

[28] Grøvle, L. et al., 2012. "Poor agreement found between self-report and a public registry on duration of sickness absence", Journal of Clinical Epidemiology, 65, $212-218$. 
[29] Heckman J. and B. Singer, 1984. " A Method for Minimizing the Impact of Distributional Assumptions in Econometric Models for Duration Data", Econometrica, 52(2): 271-320.

[30] Høgelund, J. and Holm, A. "Case management interviews and the return to work of disabled employees", Journal of Health Economics. 2006;25(3):500-519

[31] Høgelund, Jan and Holm, Anders and McIntosh, James, 2010. "Does graded return-to-work improve sick-listed workers' chance of returning to regular working hours?", Journal of Health Economics, Elsevier, vol. 29(1): 158-169.

[32] Ingram, B.F. and G.R. Neumann, 2006. "The returns to Skill", labor Economics, 13(1), 35-59.

[33] Larsen, M. 2006. "Fastholdelse og rekruttering af ældre. Arbejdspladsers indsats. (Retaining and Recruiting the Elderly: Workplace Interventions)", (Copenhagen: The Danish National Centre for Social Research), WP 06: 09.

[34] Johansson, P., Palme, M. 2005. "Moral hazard and sickness insurance", Journal of Public Economics, 89: 1879-1890.

[35] Johns, G., 1994. "How often were you absent? A review of the use of self-reported absence data", Journal of Applied Psychology, 79, 574-591.

[36] Kenkel, D., 1991. "Health Behavior, Health Knowledge and Schooling", Journal of Political Economy 99: 287-305. 
[37] Kemptner, D. H., Jurges, H. and Reinhold, S., 2011. "Changes in compulsory schooling and the causal effect of education on health: Evidence from Germany", Journal of Health Economics, 30(2):340-354.

[38] Kolenikov, S., and G. Angeles, 2009. "Socioeconomic Status Measurement With Discrete Proxy Variables: Is Principal Component Analysis A Reliable Answer?", Review of Income and Wealth, 55(1), 128-165.

[39] Lund T, Labriola M, Christensen KB, et al. 2006. "Physical work environment risk factors for long term sickness: prospective findings among a cohort of 5357 employees in Denmark", BMJ 332:449-52.

[40] Maurer, J., Socioeconomic and Health Determinants of Health Care Utilization Among Elderly Europeans: A New Look at Equity, Intensity and Responsiveness in Ten European Countries HEDG Working Paper 07/26

[41] Montgomery, James D., 1991. "Social Networks and Labor Market Outcomes: Toward an Economic Analysis", American Economic Review 81: 1408-18.

[42] Morefield, B., Ribar, D. and Ruhm, C., 2012 "Occupational Status and Health Transitions", The B.E. Journal of Economic Analysis \& Policy, 11, 3.

[43] Mroz, T., 1999. "Discrete Factor Approximations in Simultaneous Equations Models: Estimating the Impact of a Dummy Endogenous Variable on a Continuous Outcome", Journal of Econometrics, 72(2), 233-274. 
[44] Munshi, Kaivan, 2003. "Networks in the Modern Economy: Mexican Migrants in the US Labor Market", The Quarterly Journal of Economics 118: 549-99.

[45] Muurinen, J. M., 1982. "Demand for Health: A Generalized Grossman Model", Journal of Health Economics 1(1): 5-28.

[46] Muurinen, J. M. and Le Grand, 1985. "The Economic Analysis of Inequalities in Health", Social Science and Medicine, 20(10): 1029-35.

[47] Kaptyen A., Smith J. and van Soest A., 2007. "Vignettes and Self-Reports of Work Disability in the United States and the Netherlands", American Economic Review, 97(1):461-473.

[48] OECD, 2007. "Thematic review on reforming sickness and disability policies to improve wor incentives, Country Note - Denmark".

[49] Oreopoulos, P., 2006. "Estimating Average and Local Average Treatment Effects of Education when Compulsory Schooling Laws Really Matter", American Economic Review, 96(1): 152-175, March.

[50] Picone, GR., Slone, F., Chou, S.-Y., and Taylor, D., 2003. "Does higher hospital cost imply higher quality of care?", The Review of Economics and Statistics, 85(1): $51-62$.

[51] Rendall, M. 2010. "Brain versus Brawn: the realization of Women's comparative advantage", Working paper No.491, Institute for empirical research in Economics, University of Zurich. 
[52] Rosenzweig, M. R., and Schultz, T., P., 1983. "Estimating a Household Production Function: Heterogeneity, the Demand for Health Inputs and their Effects on Birth Weight", The Journal of Political Economy, 91(5): 723-746.

[53] Ruhm, C. J, 1990. "Bridge Jobs and Partial Retirement", Journal of Labor Economics, 8(4): 482-501.

[54] Stock, J. H. and Yogo M., 2005. "Testing for weak instruments in linear IV regression", In D.W.K. Andrews and J.H. Stock (eds.), Identification and inference for econometric models: Essays in honour of Thomas Rothenberg, Cambridge: Cambridge University Press.

[55] The Danish Economic Council, 2002. "Den geografisk mobilitet på arbejdsmarkedet (Geographic mobility on the labor market)", Fall 2002 report, Chapter IV.

[56] Vuong, Q. H. (1984). "Two-stage Conditional Maximum Likelihood Estimation of Econometric Models", Social Science Working Paper 538, California Institute of Technology.

[57] Wilson, C. M. and Oswald, A. J. (2005). "How Does Marriage Affect Physical and Psychological Health? A Survey of the Longitudinal Evidence", The Warwick Economics Research Paper Series (TWERPS) 728, University of Warwick, Department of Economics. 
Table 1: Destinations state after temporary work incapacity (1998-2002)

\begin{tabular}{lcccc}
\hline & $\begin{array}{c}\text { Permanent } \\
\text { work incapacity (1) }\end{array}$ & $\begin{array}{c}\text { Self- } \\
\text { sufficiency (2) }\end{array}$ & $\begin{array}{c}\text { Early } \\
\text { retirement (3) }\end{array}$ & $\begin{array}{c}\text { Other } \\
\text { destinations (4) }\end{array}$ \\
\hline All & 0.226 & 0.679 & 0.003 & 0.095 \\
Women & 0.221 & 0.707 & 0.003 & 0.078 \\
With education beyond primary & 0.198 & 0.708 & 0.002 & 0.091 \\
With a physically demanding job & 0.228 & 0.698 & 0.003 & 0.079 \\
\hline N & 14482 & 44112 & 183 & 6150 \\
\hline
\end{tabular}

Notes: (1) Disability benefit (førtidspension) and subsidized jobs (flexjob and skånejob); (2) Mostly employment;

(3) Early retirement scheme (efterløn); (4) Unemployment benefits, active labor market policies, sickness benefits.

Table 2: Factor loadings and distribution of average brawn in commuting areas

\begin{tabular}{|c|c|c|c|c|c|c|c|c|c|}
\hline \multicolumn{10}{|l|}{ Factor loadings } \\
\hline Strength requirement & 0.88 & & & & & & & & \\
\hline Stooping/Kneeling/Crouching/Crawling & 0.81 & & & & & & & & \\
\hline Climbing/Balancing & 0.78 & & & & & & & & \\
\hline Enviromental exposure & 0.78 & & & & & & & & \\
\hline Outdoor work & 0.68 & & & & & & & & \\
\hline Repetitive work & 0.30 & & & & & & & & \\
\hline \multicolumn{10}{|l|}{ Average brawn } \\
\hline Percentile & $1 \%$ & $5 \%$ & $10 \%$ & $25 \%$ & $50 \%$ & $75 \%$ & $90 \%$ & $95 \%$ & $99 \%$ \\
\hline Male & 86.7 & 95.7 & 99.6 & 102.1 & 109.3 & 117.6 & 132.6 & 157.1 & 193.25 \\
\hline Female & 58.5 & 69.4 & 71.1 & 72.4 & 75.2 & 80.8 & 83.8 & 85.6 & 87.3 \\
\hline
\end{tabular}


Table 3: Descriptive statistics of the all sample

\begin{tabular}{lcccc}
\hline & \multicolumn{2}{c}{ Women } & \multicolumn{1}{c}{ Men } \\
\hline Variables: & All & Education beyond primary & All & Education beyond primary \\
\hline Temporary work incapacity & 0.0340 & 0.0281 & 0.0283 & 0.0202 \\
Years of education & 10.7272 & 12.0451 & 10.8406 & 12.5959 \\
Education beyond primary & 0.5918 & & 0.4855 & 53.2460 \\
Age & 53.3294 & 53.1016 & 53.4342 & 0.1274 \\
Physically demanding job & 0.1198 & 0.0818 & 0.2477 & 96.0558 \\
Average brawn at the commuting area & 67.4503 & 66.57455 & 97.8857 & 0.7857 \\
Married & 0.7493 & 0.7402 & 0.7735 & 0.4898 \\
Born in city & 0.4069 & 0.4681 & 0.4043 & 0.3245 \\
Reform*Born in city & 0.2684 & 0.3180 & 0.2602 & 0.0947 \\
Cohort (1943) & 0.0996 & 0.0851 & 0.1075 & 0.1098 \\
Cohort (1944) & 0.1138 & 0.1002 & 0.1207 & 0.1218 \\
Cohort (1945) & 0.1258 & 0.1152 & 0.1313 & 0.1353 \\
Cohort (1946) & 0.1352 & 0.1308 & 0.1384 & 0.1338 \\
Cohort (1947) & 0.1381 & 0.1362 & 0.1344 & 0.1337 \\
Cohort (1948) & 0.1318 & 0.1372 & 0.1272 & 0.1303 \\
Cohort (1949) & 0.1265 & 0.1410 & 0.1203 & 0.1406 \\
Cohort (1950) & 0.1293 & 0.1542 & 0.1203 & 597433 \\
\hline N & 1105809 & 647598 & 1230614 & \\
\hline
\end{tabular}

Table 4: Descriptive statistics of the sample of individuals with temporary work incapacity

\begin{tabular}{|c|c|c|c|c|}
\hline & \multicolumn{2}{|r|}{ Women } & \multicolumn{2}{|r|}{ Men } \\
\hline Variables: & All & Education beyond primary & All & Education beyond primary \\
\hline Permanent work incapacity & 0.2349 & 0.2059 & 0.2219 & 0.1904 \\
\hline Years of education & 10.1411 & 11.7620 & 9.8879 & 11.7150 \\
\hline Education beyond primary & 0.2256 & & 0.1636 & \\
\hline Age & 53.7681 & 53.8967 & 53.8150 & 54.0297 \\
\hline Physically demanding job & 0.1711 & 0.1298 & 0.3457 & 0.2148 \\
\hline Average brawn at the commuting area & 67.9019 & 66.8856 & 99.1773 & 97.0483 \\
\hline Married & 0.7142 & 0.6510 & 0.7262 & 0.7442 \\
\hline Born in city & 0.3985 & 0.4737 & 0.3810 & 0.4672 \\
\hline Reform*Born in city & 0.2591 & 0.3143 & 0.2352 & 0.2918 \\
\hline Cohort (1943) & 0.1008 & 0.0948 & 0.1216 & 0.1161 \\
\hline Cohort (1944) & 0.1199 & 0.1075 & 0.1313 & 0.1249 \\
\hline Cohort (1945) & 0.1308 & 0.1167 & 0.1362 & 0.1326 \\
\hline Cohort (1946) & 0.1362 & 0.1377 & 0.1430 & 0.1458 \\
\hline Cohort (1947) & 0.1406 & 0.1403 & 0.1327 & 0.1499 \\
\hline Cohort (1948) & 0.1266 & 0.1279 & 0.1179 & 0.1157 \\
\hline Cohort (1949) & 0.1232 & 0.1305 & 0.1104 & 0.1149 \\
\hline Cohort (1950) & 0.1220 & 0.1446 & 0.1070 & 0.1001 \\
\hline $\mathrm{N}$ & 33297 & 16027 & 31760 & 10593 \\
\hline
\end{tabular}


Figure 1: The school reform and the share of individuals with at least primary education

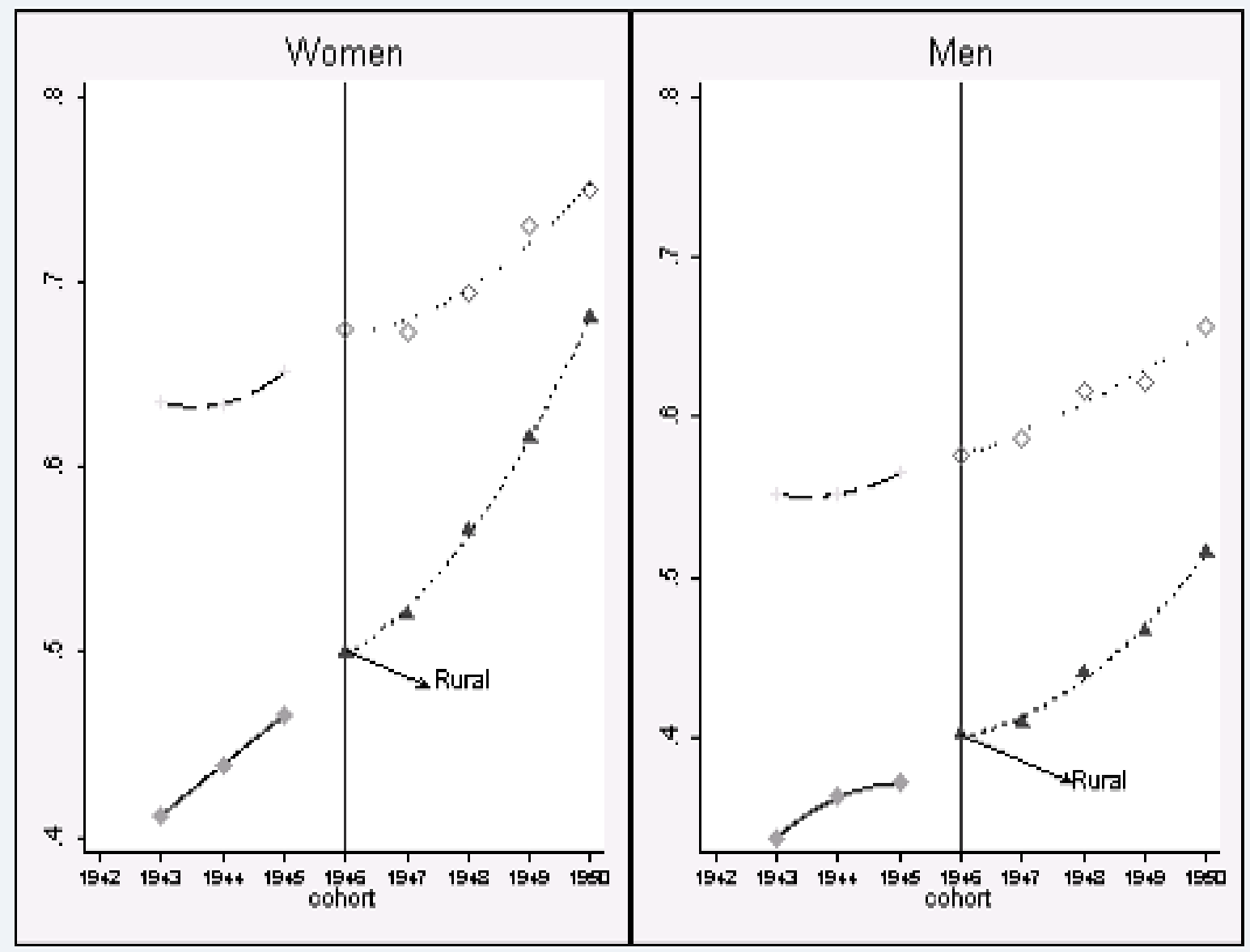

Notes: Trends before and after the school reform are calculated with a quadratic fit. 
Figure 2: Temporary work incapacity rates by type of occupation

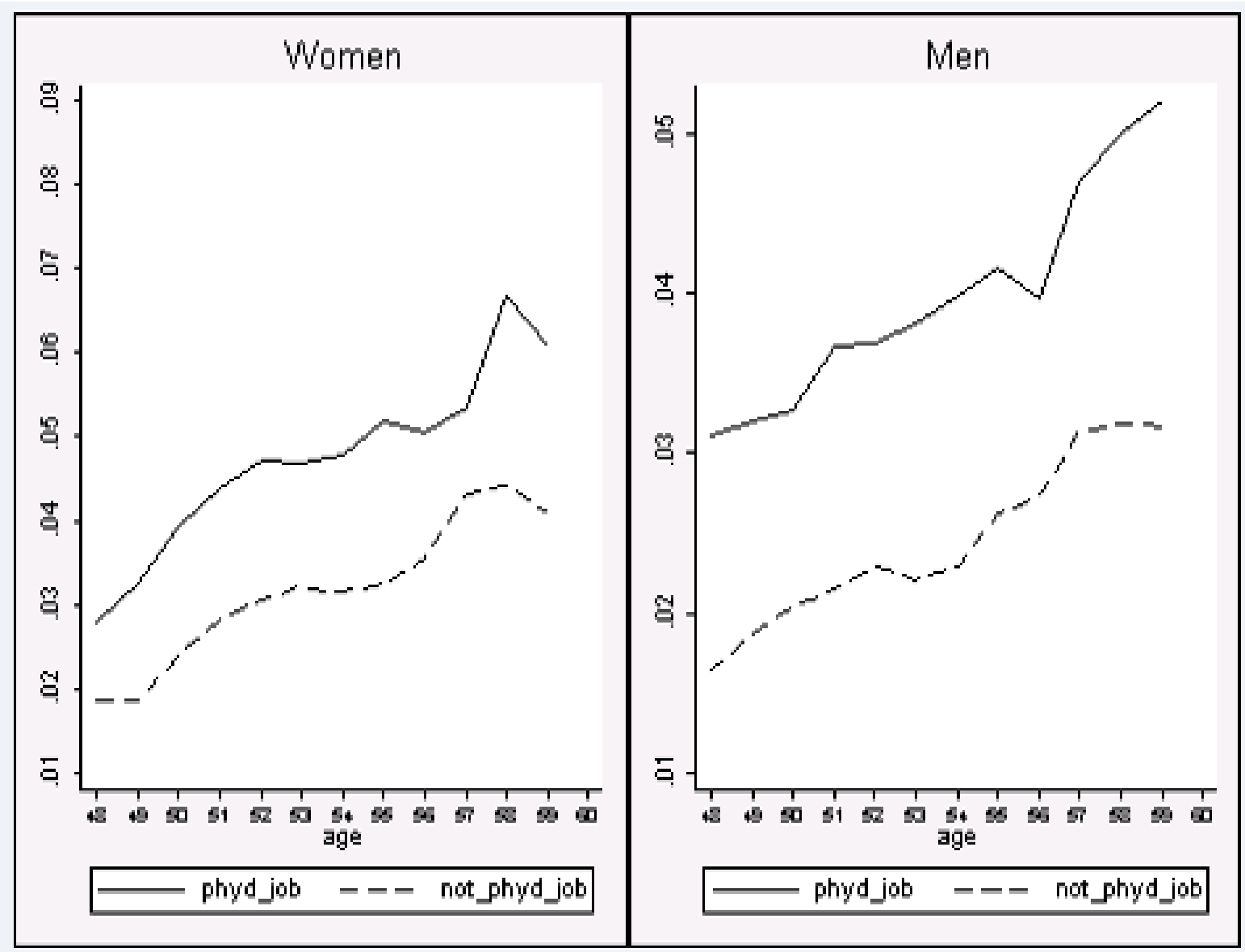

Notes: Phyd_job and not_phyd_job stand respectively for physically and not physically demanding job. 


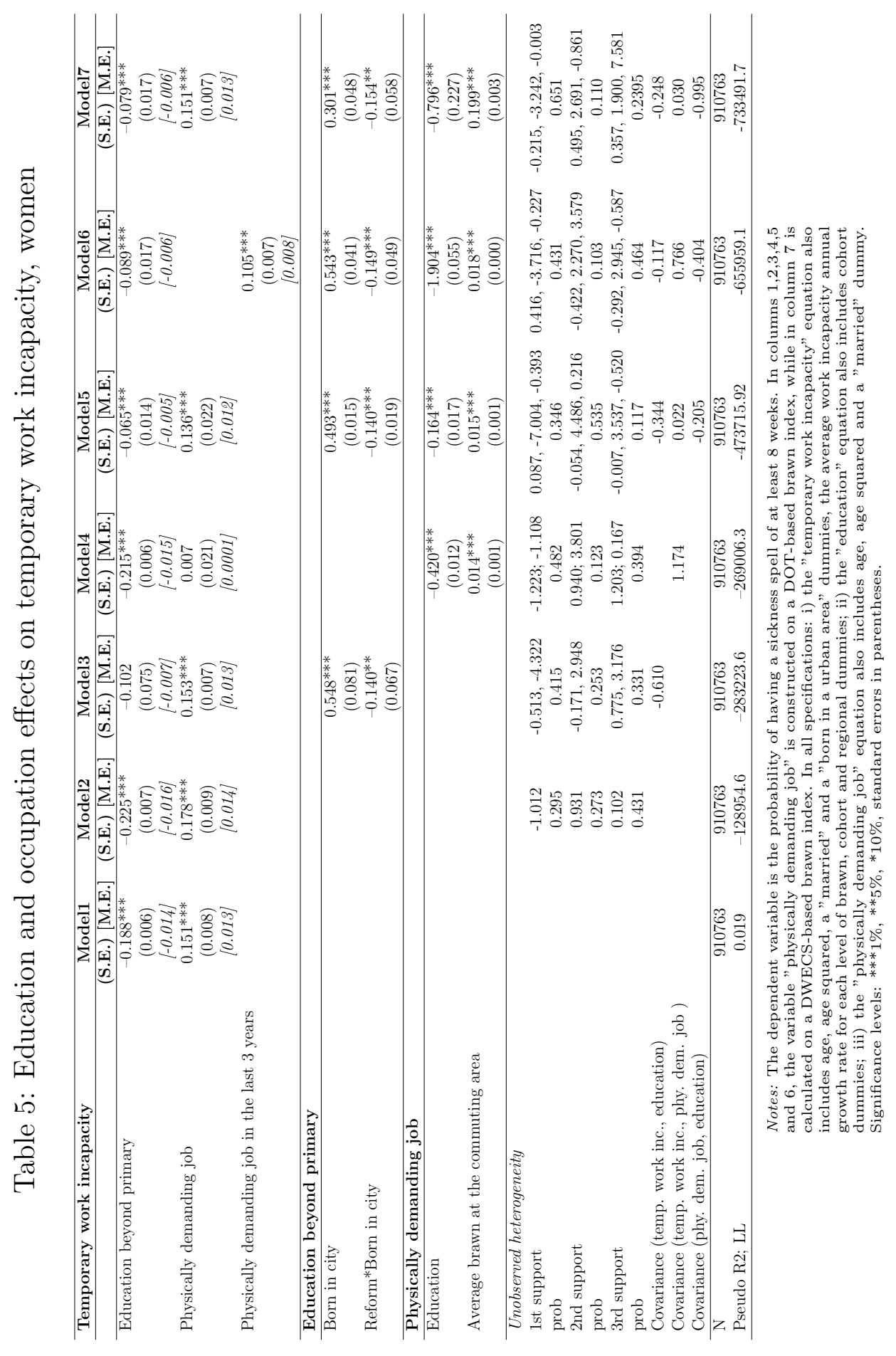




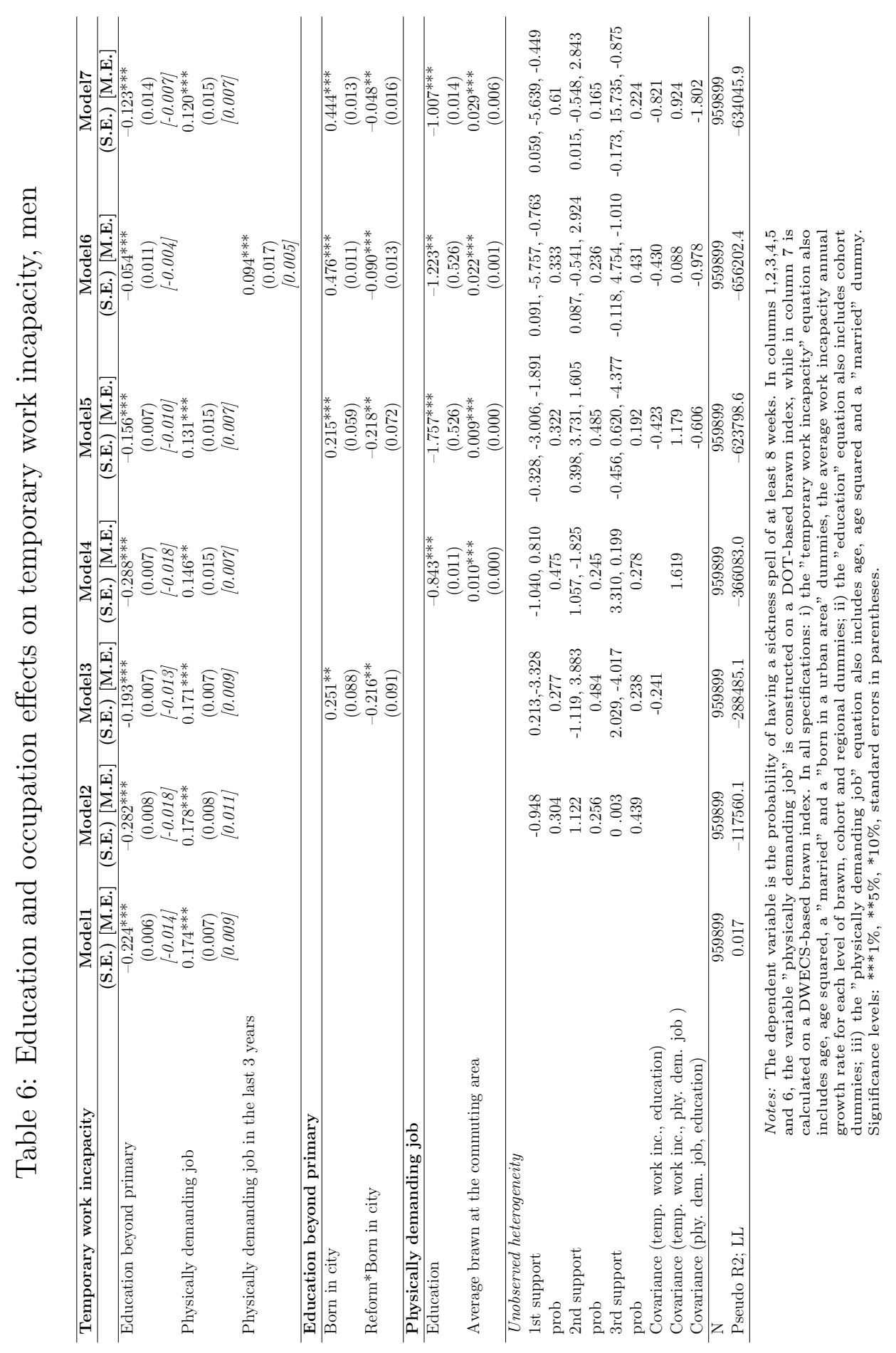


Figure 3: Marginal effects of physically demanding job on temporary work incapacity by age, women

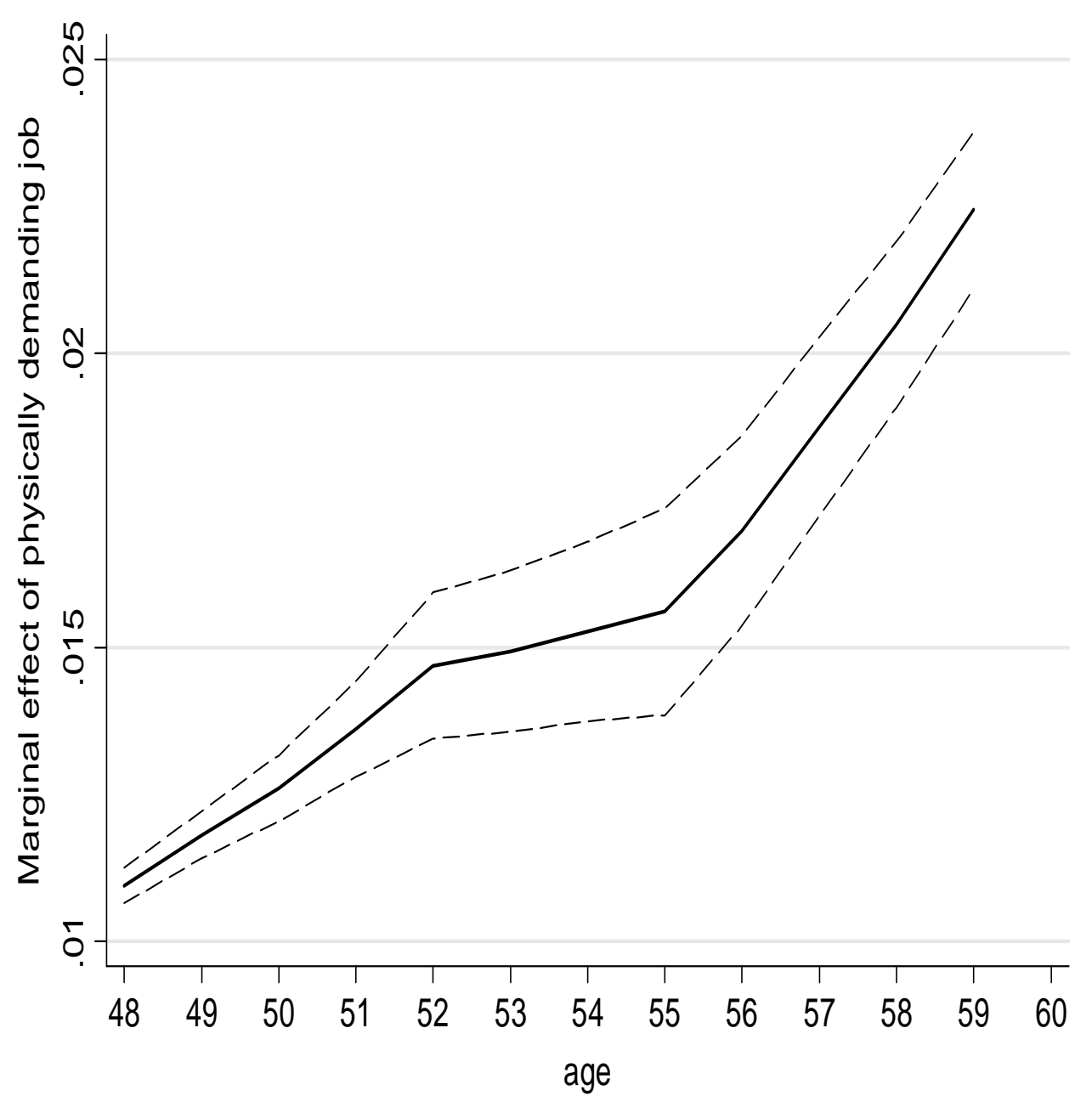


Figure 4: Marginal effects of physically demanding job on temporary work incapacity by age, men

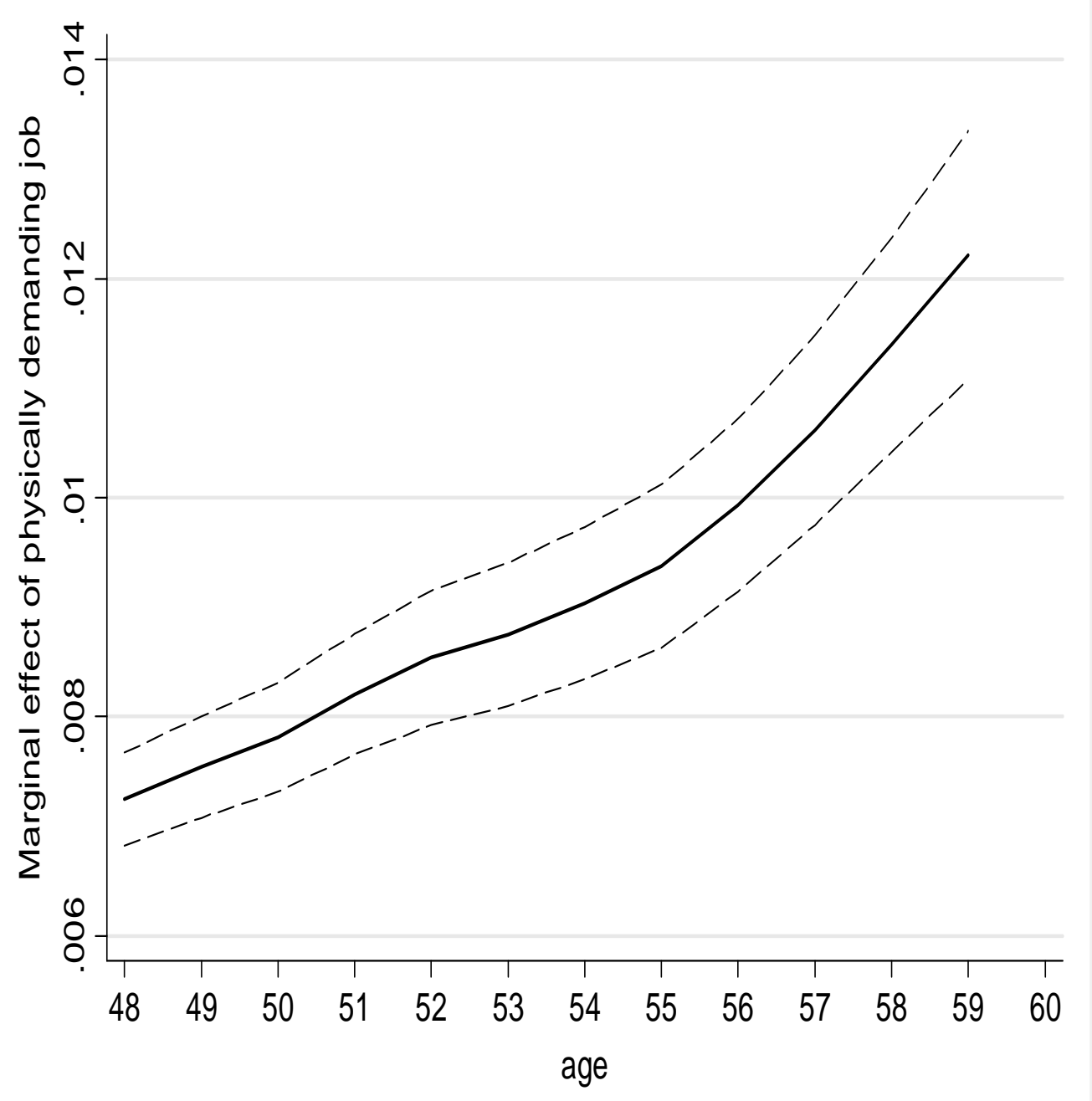




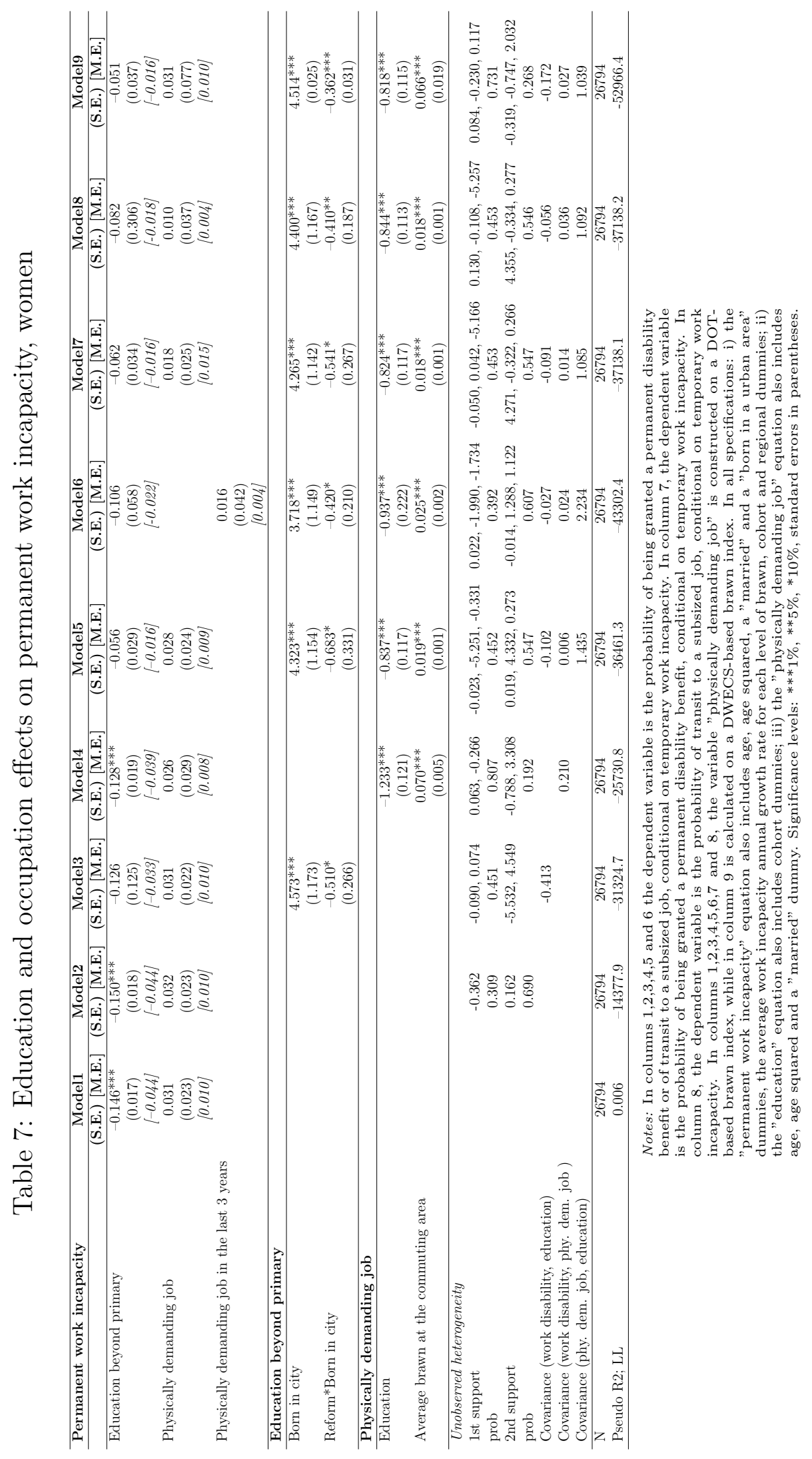




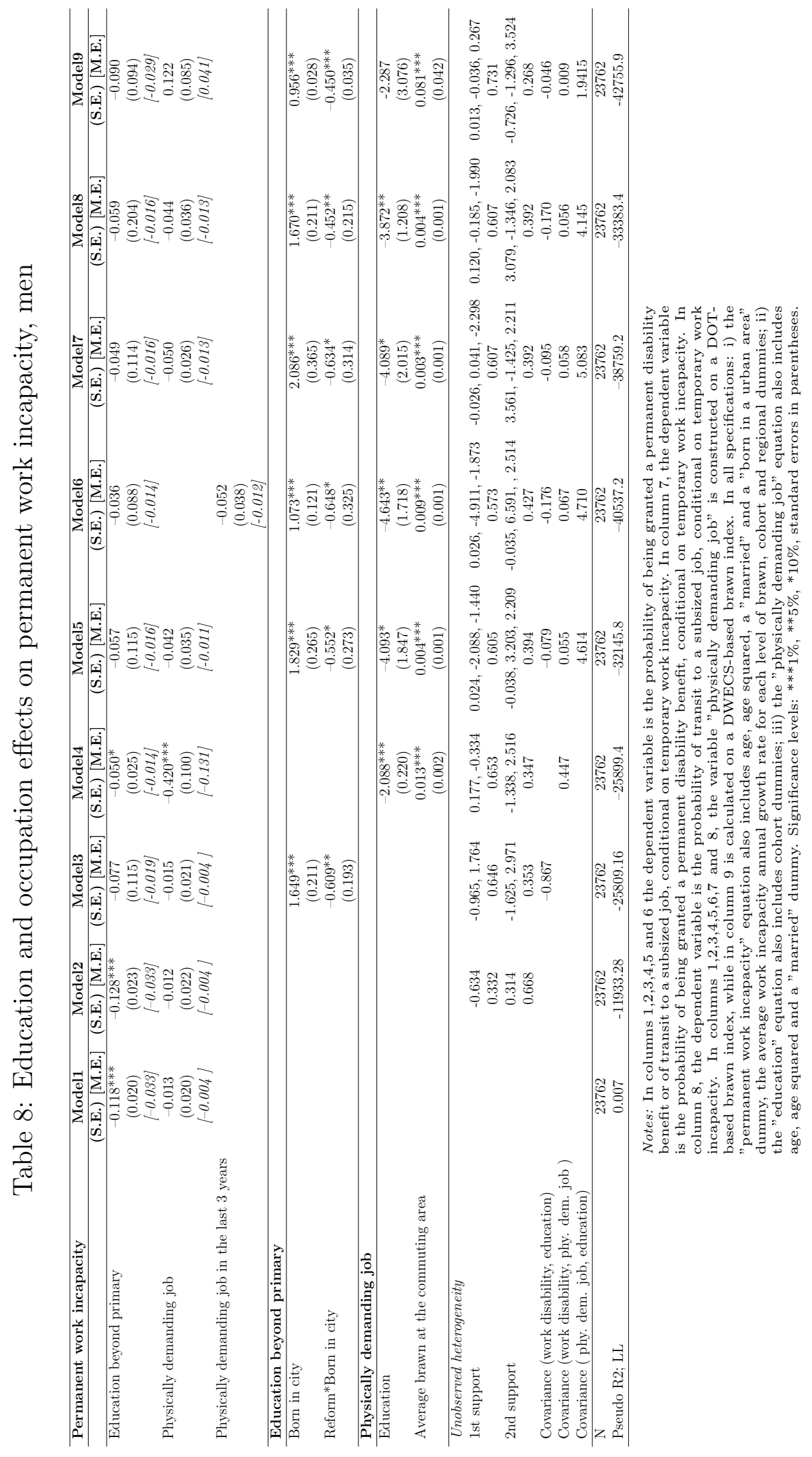

